\title{
Efectos citotoxicos in vitro de extractos y fracciones de Bursera tomentosa (Jacq.) Triana \& Planch., Burseraceae, frente a lineas celulares tumorales humanos
}

\author{
Jorge E. Robles Camargo, ,', Alba N. Téllez Alfonso, ${ }^{1}$ Ronald A. Rojas-Rozo, ${ }^{1}$ \\ Clemencia de Castro, ${ }^{2}$ Tulia Riveros de Murcia $^{2}$
}

\author{
${ }^{1}$ Departamento de Quimica, Grupo de Investigación Fitoquímica, Pontificia Universidad Javeriana, Bogotá, \\ Colombia, \\ ${ }^{2}$ Fundación Universitaria San Martín. Bogotá, Colombia.
}

\begin{abstract}
RESUMO: "Efeitos citotóxicos in vitro de extratos e frações de Bursera tomentosa (Jacq.) Triana \& Planch., Burseraceae, frente a linhagens celulares tumorais humanos". A atividade citotóxica de extratos frações e subfrações obtidas das folhas e cascas de Bursera tomentosa (Jacq.) Triana \& Planch., Burseraceae, foram preliminarmente avaliados pelo método MTT frente a linhagens celulares tumorais CSC-1595 e Colo 205. Os resultados mostraram que a subfração diclorometano-metanol (9.5:0.5), obtidos a partir da fração acetato de etila do extrato em éter de petróleo das folhas, como sendo a que apresenta substâncias bioativas com forte atividade citotóxica, taxa de viabilidade de $3 \%$ e de $15,3 \%$ na concentração de $30 \mu \mathrm{g} / \mathrm{mL}$ em linhagens de células tumorais humanas Colo 205 e CSC-1595, respectivamente.
\end{abstract}

Unitermos: Actividads citotóxica, linhagens celulares tumorais, Bursera tomentosa.

\begin{abstract}
In vitro cytotoxicity of extracts and fractions of Bursera tomentosa (Jacq.) Triana \& Planch., Burseraceae, against human tumor cell." To the extracts, fractions and subfractions obtained from leaves, flowers and bark of Bursera tomentosa (Jacq.) Triana \& Planch., Burseraceae, its preliminary cytotoxic activity against to the cellular lines CSC-1595 and Colo 205 were evaluated, following the MTT method. The results showed that dichloromethane-methanol (9.5:0.5) subfraction obtained of ethyl acetate part from petroleum extract of leaves, like to display the bioactives substances with a strong cytotoxic activity, showing viability percentage of $3 \%$ and $15,3 \%$ to the concentration $30 \mu \mathrm{g} / \mathrm{mL}$ in human tumor cellular lines Colo 205 and CSC-1595 respectively.
\end{abstract}

Keywords: Cytotoxic activity, Tumoral cellular lines, Bursera tomentosa.

\begin{abstract}
RESUMEN: A los extractos, fracciones y subfracciones obtenidos de hojas, flores y corteza de Bursera tomentosa (Jacq.) Triana \& Planch., Burseraceae, se les evalúo su actividad citotóxica preliminar frente a las líneas celulares CSC-1595 y Colo 205, siguiendo el método de fraccionamiento guiado por bioensayo de citotoxicidad MTT. Los resultados obtenidos de esta prueba muestran a la subfracción en diclorometano-metanol (9.5:0.5) obtenida de la fracción acetato de etilo del extracto en éter de petróleo de hojas, como la que presentó las sustancias bioactivas con una marcada actividad citotóxica, con porcentajes de viabilidad del $3 \%$ y $15.3 \%$ a la concentración $30 \mu \mathrm{g} / \mathrm{mL}$ en las líneas tumorales humanas Colo 205 y CSC-1595 respectivamente.
\end{abstract}

Palabras clave: Actividad citotóxica, líneas celulares tumorales, Bursera tomentosa.

\section{INTRODUCCIÓN}

La especie Bursera tomentosa (Jacq.) Triana \& Planch., Burseraceae, conocida como "tatamaco" y/o "Sasafrás macho", posee un gran potencial curativo dentro de la medicina botánica tradicional; es un arbusto de $5 \mathrm{~m}$ de alto y $14 \mathrm{~cm}$ de DAP (Diámetro a la altura del pecho), de los bosques secos, con copa compacta y follaje de color verde lustroso (Martínez, 1998). Pertenece a la familia Burseraceae, familia a la cual se le ha demostrado propiedades farmacológicas importantes entre las que se destacan la actividad anti-inflamatoria y antiviral de algunas resinas (Duwiejua \& Zeitlin, 1993; Poehland \& Carte, 1987), su acción contra nematodos, como 
Meloidogyne incognita, (Sharma \& Trivedi, 1991), sus propiedades antifúngicas y antimicrobianas, (Claeson \& Radstrom, 1992; Lima \& Gompertz, 1992; Desta, 1993; Rahalison \& Hamburger, 1993; Gray et al., 1997); sus efectos hepatoprotectores, además del interés en estudios de leucemia y carcinomas (Jolad \& Wiedhopf, 1977). A extractos de Bursera graveolens se le han realizado pruebas antimicrobianas, antiinflamatorias y estudios fitoquímicos (Robles et al., 2005). Adicionalmente se ha detectado en los géneros Bursera y Protium sustancias antitumorales y estimulantes del sistema nervioso central. Para la especie Bursera tokinensis, se identifico el compuesto 4'-dimetildesoxipodofilotoxina como responsable de la actividad citotóxica frente a las líneas celulares $\mathrm{KB}$ (carcinoma humano oral), Colo 2 (cáncer de colon humano) y LNCaP (cáncer de próstata humano) (Jutiviboonsuk et al., 2005). Se ha reportado además actividad inhibitoria del extracto etanólico de la corteza de Bursera odorata frente a líneas celulares HCT-116 (células de cáncer colorectal humano) (Murillo-Álvarez et al., 2001).

En este estudio se evalúo el efecto citotóxico de los extractos y fracciones obtenidas de la especie vegetal, frente a dos líneas celulares, la línea celular Colombiana CSC-1595 y la línea celular Colo 205 (adenocarcinoma de colon humano) del National Cancer Research Institute de los Estados Unidos. Este estudio constituye una etapa primordial en el tamizaje de sustancias promisorias para el tratamiento del cáncer.

\section{MATERIALES Y MÉTODOS}

\section{Material vegetal}

La especie vegetal, Bursera tomentosa (Jacq.) Triana \& Planch., Burseraceae, fue colectada en la vereda la Balastrera, vía al Cerro de la cruz en el municipio de Agua de Dios (Cundinamarca). Un ejemplar se depositó en el Herbario Nacional de Colombia bajo el No. Col 480958 .

\section{Extracción y fraccionamiento}

Se colectaron cerca de $5 \mathrm{~kg}$ de peso fresco entre hojas, corteza y flores. Posteriormente se realizo la extracción por maceración en frío, primero con éter de petróleo y luego con etanol; los fraccionamientos se realizaron en columna tipo flash. Se realizaron pruebas químicas y monitoreos cromatográficos con diferentes fases estacionarias y móviles. Los extractos en petrol de cada uno de los órganos secos y pulverizados de $B$. tomentosa (32 g), se filtró y concentró, resuspendiendo el residuo seco en $\mathrm{MeOH}$. El extracto floculado (19 g) se le realizó fraccionamiento líquido-líquido con petrol, $\mathrm{CH}_{2} \mathrm{Cl}_{2}, \mathrm{AcOEt}$ y EtOH. El subfraccionamiento de las fracciones activas obtenidas en acetato de etilo de hojas y corteza, se realizó por cromatografía en columna con sílica gel utilizando como eluyentes: diclorometano, diclorometano:metanol en proporciones $(9.5: 0.5),(9: 1)$ y $(1: 1)$. Los extractos en etanol se percolaron en columna con fase estacionaria RP18 y eluída con las fases móviles: metanol-agua (10:2), metanol, metanol-diclorometano (1:1) y diclorometano.

\section{Cultivos celulares}

Se utilizaron las líneas celulares neoplásicas, la línea celular Colombiana CSC-1595 derivada de tejido tumoral de seno, obtenida en el Laboratorio de Biología Experimental del Instituto Nacional de Cancerología de Colombia a partir del tumor de una paciente de 77 años. (Téllez et al., 2006) y la línea celular Colo 205 (adenocarcinoma de colon humano) del National Cancer Research Institute de los Estados Unidos.

Los cultivos se realizan en cajas de 96 pozos, con medio L-15 (Sigma) suplementado con $10 \%$ de suero fetal bovino (Gibco) y $100 \mu \mathrm{L} / 10 \mathrm{~mL}$ penicilina estreptomicina y neomicina (Sigma 5000U, $5 \mathrm{mg}$ estreptomicina y 10 $\mathrm{mg}$ neomicina/mL). Las células de las diferentes líneas y cultivos secundarios se resuspenden en el medio de cultivo de tal forma que haya 40000 células en $100 \mu \mathrm{L}$ por pozo. Los cultivos se incuban a $37{ }^{\circ} \mathrm{C}$ y $5 \%$ de $\mathrm{CO}_{2}$ y $100 \%$ de humedad relativa por $24 \mathrm{~h}$ con el objeto de tener un buen crecimiento celular.

\section{Bioensayo}

Los ensayos citotóxicos se realizaron en el Laboratorio de Cultivo Celular del Departamento de Bioquimica de la Universidad Javeriana. La evaluación de la viabilidad celular fue realizada mediante el método de fraccionamiento guiado por el bioensayo de viabilidad celular MTT (Bromuro de 3-(4,5-dimetiltiazol-2-ilo)-2,5difeniltetrazolio), ensayo que se encuentra ampliamente referenciado en la literatura (Studzinski, 1999). Se tomó como control negativo las células con medio de cultivo obteniéndose el $100 \%$ de viabilidad del ensayo, se hizo control al solvente DMSO $0.2 \%$ y como control positivo Doxorubicina a $0.08 \mu \mathrm{g} / \mathrm{mL}$.

Los extractos totales se probaron a concentraciones de $300 \mu \mathrm{g} / \mathrm{mL}$, teniendo en cuenta el grado de mezcla y la mínima cantidad de los metabolitos presentes en cada uno de ellos. Al fraccionar y subfraccionar los extractos activos, se probaron a concentraciones menores, considerando la disminución de la mezcla y una cantidad mayor de los posibles principios activos. Se consideraron activos los extractos, fracciones y subfracciones que presentaron en los ensayos un porcentaje de viabilidad igual o inferior al 50\%. Para cada prueba de citotoxicidad, se realizó en el análisis estadístico una prueba de normalidad, de homogeneidad de varianzas y significancia.

Para la subfracción activa se realizaron las pruebas químicas cualitativas de identificación de los tipos de metabolitos presentes: pruebas de Baljet, LiebermannBurchard, Shinoda, espuma y Drangendorff. 


\section{RESULTADOS Y DISCUSIÓN}

Los extractos en petrol de hojas y corteza frente a la línea celular CSC-1595, presentaron porcentajes de viabilidad de $7,45 \%$ y $21,83 \%$ respectivamente, los extractos etanólicos de corteza y hojas 5,64\%, y 24,32\%, y los extractos obtenidos de flores no presentaron una acción significativa con porcentajes de viabilidad superior al $80 \%$, como se muestra en la Figura 1. Los análisis estadísticos mostraron los siguientes resultados: $\mathrm{K}-\mathrm{W}=37.1672, \mathrm{GL}=8$, $p<0.05, \mathrm{~N}=45$.

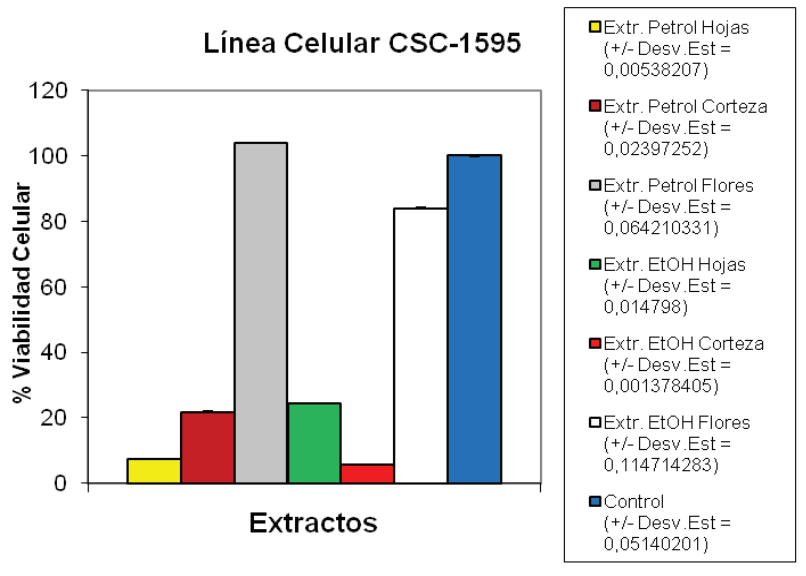

Figura 1. Efecto citotóxico de los extractos de Bursera tomentosa frente a la línea celular CSC-1595 a una concentración de 300 $\mu \mathrm{g} / \mathrm{mL}$.

Los extractos considerados activos se sometieron a fraccionamiento en columna tipo flash con diferentes fases estacionarias y fases móviles. Los extractos en petrol se percolaron en columna empacada con sílica gel y eluída con los solventes éter de petróleo, diclorometano, acetato de etilo y etanol, obteniéndose tanto para corteza como para hojas cuatro fracciones, una por cada fase móvil. De igual forma los extractos en etanol se percolaron en columna con fase estacionaria RP-18 y eluída con las fases móviles: metanol-agua (10:2), metanol, metanol-diclorometano $(1: 1)$ y Diclorometano. Estas fracciones se evaluaron a la concentración de $120 \mu \mathrm{g} / \mathrm{mL}$. En las fracciones obtenidas del extracto en petrol, se observó la mayor actividad en las fracciones de acetato de etilo, de los dos órganos; con porcentajes de viabilidad celular de $2.97 \%$ para la fracción obtenida de la corteza y $5.86 \%$ para la fracción obtenida de las hojas. En contraste, el resto de fracciones presentaron porcentajes de viabilidad poco significativos con valores superiores al 70\%, como se muestra en la Figura 2. Los análisis estadísticos realizados mostraron los siguientes resultados: $\mathrm{K}-\mathrm{W}=51.981, \mathrm{GL}=9, p<0.05, \mathrm{~N}=60$.

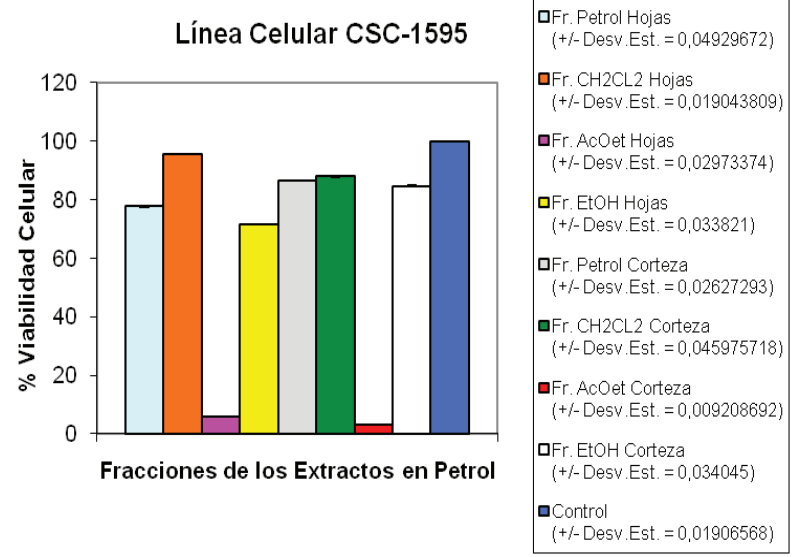

Figura 2. Efecto citotóxico de las fracciones de los extractos en éter de petróleo de hojas y corteza de Bursera tomentosa frente a la línea celular CSC-1595 a una concentración de $120 \mu \mathrm{g} / \mathrm{mL}$.

Al comparar por cromatografía en capa delgada (F.E: Si-gel, y F.M: $\mathrm{CH}_{2} \mathrm{Cl}_{2}$ ), en las fracciones acetato de etilo del extracto en éter de petróleo de hojas y corteza que presentaron la mayor actividad citotóxica se detectaron amplias diferencias en cuanto a los metabolitos. El subfraccionamiento de las fracciones activas en acetato de etilo de hojas y corteza, se realizó por cromatografía en columna con sílica gel utilizando como eluyentes: diclorometano, diclorometano:metanol en proporciones (9.5:0.5), (9:1) y (1:1). Cada una de las subfracciones fue evaluada a concentraciones de 60 y $30 \mu \mathrm{g} / \mathrm{mL}$.

Los resultados muestran para las subfracciones de corteza una pérdida de la actividad citotóxica al presentar porcentajes de viabilidad celular superiores del 50\%. Así: $51.40 \%$ para la subfracción en diclorometano a $60 \mu \mathrm{g} / \mathrm{mL}$ y de $85.42 \%$ a $30 \mu \mathrm{g} / \mathrm{mL}$; para la subfracción en diclorometano-metanol (9.5:0.5), se obtuvieron valores de $91.36 \%$ a $60 \mu \mathrm{g} / \mathrm{mL}$ y de $77.11 \%$ a $30 \mu \mathrm{g} / \mathrm{mL}$; en la subfracción diclorometano-metanol $(9: 1)$ se obtuvieron valores de $73.04 \%$ a $60 \mu \mathrm{g} / \mathrm{mL}$ y de $81.98 \%$ a $30 \mu \mathrm{g} / \mathrm{mL}$; y para la subfracción en diclorometano-metanol (1:1) se obtuvieron valores de $79.48 \%$ a $60 \mu \mathrm{g} / \mathrm{mL}$ y de $71.04 \%$ a $30 \mu \mathrm{g} / \mathrm{mL}$ (Figura 3). De lo cual es posible inferir, que al momento de subfraccionar la fracción, esta pudo haber perdido su efecto citotóxico, posiblemente por perdida de la sinergia entre las subfracciones (Figura 3) (Hostettmann \& Hamburguer, 1991). Los análisis estadísticos realizados mostraron los siguientes resultados: $\mathrm{K}-\mathrm{W}=23,019, \mathrm{GL}=9$, $p<0.05, \mathrm{~N}=60$.

Mientras que en las subfracciones de la fracción en acetato de etilo, obtenida a partir del extracto en petrol de hojas, los resultados indican porcentajes de viabilidad celular para la subfracción en diclorometano-metanol (9.5:0.5) valores de $7.09 \%$ a $60 \mu \mathrm{g} / \mathrm{mL}$ y de $15.13 \%$ a $30 \mu \mathrm{g} / \mathrm{mL}$ considerándose la fracción de mayor actividad como se muestra en la Figura 4. Los análisis estadísticos realizados mostraron los siguientes resultados $\mathrm{F}=9.6452$, $\mathrm{GL}=9, p<0.05, \mathrm{~N}=57$. 


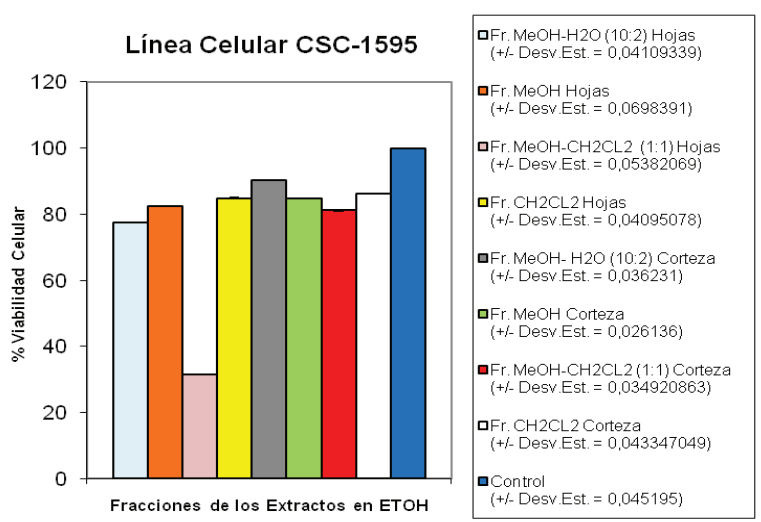

Figura 3. Efecto citotóxico de las subfracciones de la fracción activa AcOEt de la corteza de Bursera tomentosa frente a la línea celular CSC-1595 a concentraciones de 60 y $30 \mu \mathrm{g} / \mathrm{mL}$ por cada subfracción.
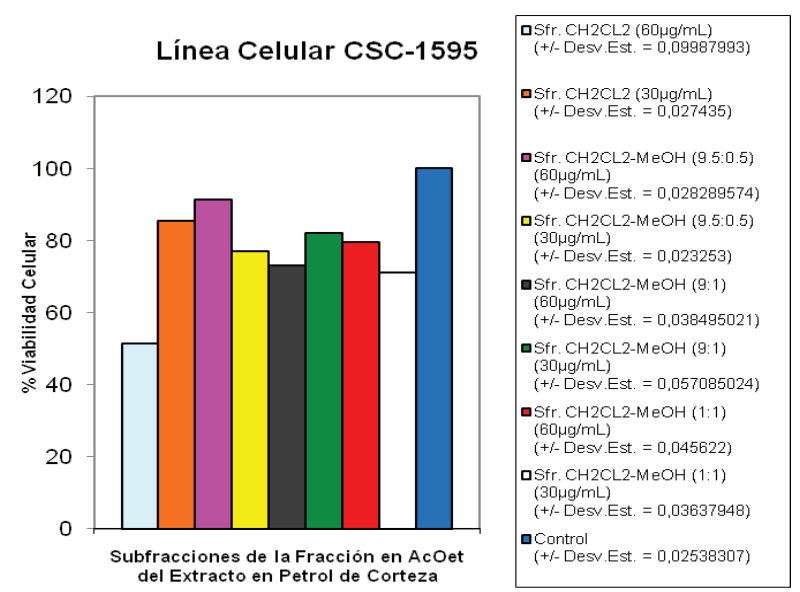

Figura 4. Efecto citotóxico de las subfracciones de la fracción activa AcOEt de las hojas de Bursera tomentosa frente a la línea celular CSC-1595 a concentraciones de 60 y $30 \mu \mathrm{g} / \mathrm{mL}$ por cada subfracción.

Las fracciones obtenidas a partir de los extractos en etanol de hojas y corteza evaluadas a la concentración de $120 \mu \mathrm{g} / \mathrm{mL}$, mostraron los siguientes resultados: las fracciones en metanol- $\mathrm{H}_{2} \mathrm{O}(10: 2)$ de hojas y corteza presentaron viabilidad en un $77.49 \%$ y $90.35 \%$ respectivamente; las fracciones en $\mathrm{MeOH}$ un $82.43 \%$ y $84.86 \%$, las fracciones $\mathrm{MeOH}: \mathrm{CH}_{2} \mathrm{Cl}_{2}(1: 1)$ un $31.62 \%$ y $81.17 \%$. Como se pudo observar no se obtuvieron valores realmente significativos comparados con el extracto inicial, exceptuando la fracción $\mathrm{MeOH}: \mathrm{CH}_{2} \mathrm{Cl}_{2} \quad(1: 1)$ de hoja (Figura 5). Los análisis estadísticos realizados mostraron los siguientes resultados: $\mathrm{F}=29.450, \mathrm{GL}=9$, $p<0.05, \mathrm{~N}=58$.

En la Figura 6 se observan los resultados obtenidos en los ensayos de actividad biológica frente a la línea celular Colo 205. Las fracciones elegidas para esta prueba fueron aquellas que presentaron mayor actividad biológica frente a la línea celular CSC-1595. La subfracción en diclorometano-metanol $(9.5: 0.5)$ obtenida de la fracción acetato de etilo de hojas a concentraciones de 60 y $30 \mu \mathrm{g} / \mathrm{mL}$ presentaron los valores de viabilidad más significativos, de $1.65 \%$ y $1.84 \%$ respectivamente, lo que sugiere que la línea celular Colo 205 es más sensible a esta subfracción que la línea celular CSC-1595. Para el caso de las fracciones en acetato de etilo tanto de las hojas como de la corteza y diclorometano-metanol (1:1) de las hojas, probadas todas a $100 \mu \mathrm{g} / \mathrm{mL}$, se observaron porcentajes de viabilidad superiores al $100 \%$ del control, lo que permite suponer que en estas fracciones se encuentren sustancias que promuevan la proliferación en esta línea celular. Los análisis estadísticos realizados mostraron los siguientes resultados: $\mathrm{F}=39.244, \mathrm{GL}=9, p<0.05, \mathrm{~N}=60$.
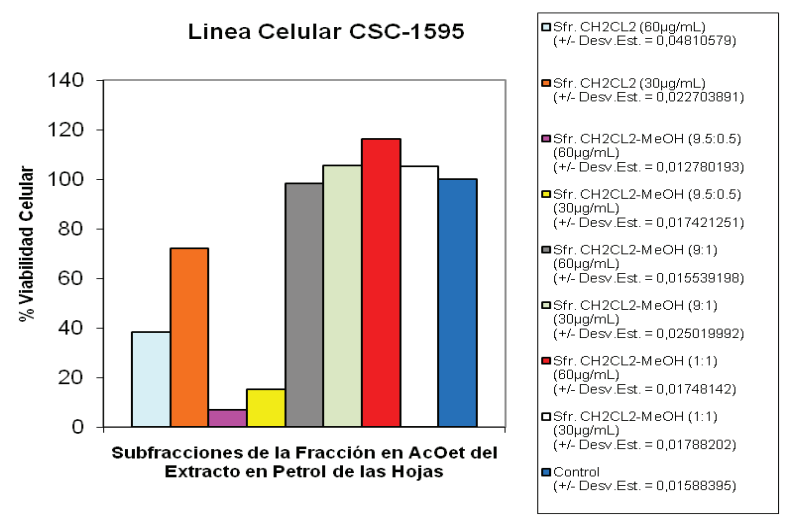

Figura 5. Efecto citotóxico de las fracciones obtenidas a partir de los extractos en etanol de hojas y corteza de Bursera tomentosa frente a la línea celular CSC-1595 a una concentración de 120 $\mu \mathrm{g} / \mathrm{mL}$.

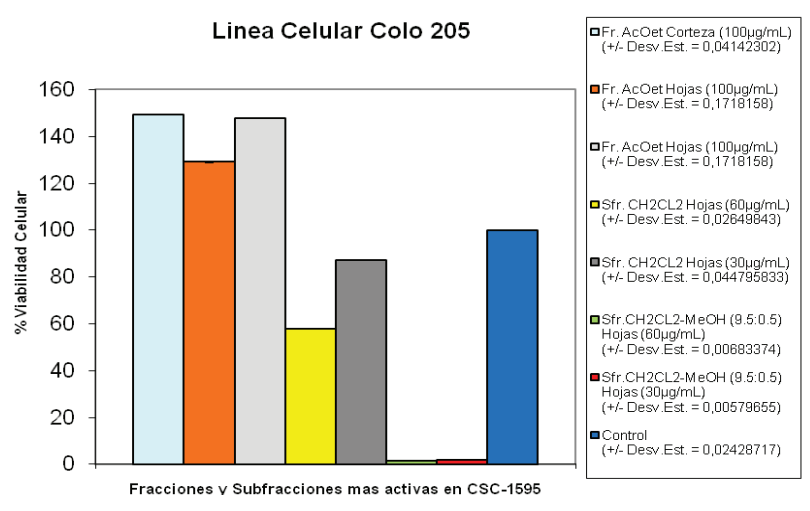

Figura 6. Efecto citotóxico de las fracciones y subfracciones que presentaron mayor actividad biológica frente a la línea celular CSC-1595, y probadas contra la línea celular Colo 205.

A partir de la subfracción diclorometano-metanol $(9,5: 0,5)$, activa para las dos líneas celulares se obtuvieron tres subfracciones, después de realizar un fraccionamiento en columna con sílica gel 60 con las siguientes fases móviles: diclorometano, diclorometano-metanol $(9,5: 0,5)$ 
y metanol. Estas subfracciones fueron probadas a las concentraciones de 80 y $40 \mu \mathrm{g} / \mathrm{mL}$ en las dos líneas celulares, Colo 205 (Figura 7) y CSC-1595 (Figura 8). La subfracción en $\mathrm{MeOH}$ no mostró actividad citotóxica en las dos líneas celulares probadas por presentar \% de viabilidad celular superiores al $80 \%$ de la concentración de $40 \mu \mathrm{g} / \mathrm{mL}$. En la línea celular Colo 205, la subfracción en diclorometano presentó porcentajes de viabilidad de $20.73 \%$ a una concentración de $80 \mu \mathrm{g} / \mathrm{mL}$ y de $8.69 \%$ a $40 \mu \mathrm{g} / \mathrm{mL}$. La subfracción en diclorometano-metanol (9.5:0.5) presentó porcentajes de viabilidad de $4.81 \%$ a 80 $\mu \mathrm{g} / \mathrm{mL}$ y de $28.56 \%$ a $40 \mu \mathrm{g} / \mathrm{mL}$. Al presentar estas últimas subfracciones una actividad menor a la fracción original $\left(\mathrm{CH}_{2} \mathrm{Cl}_{2}: \mathrm{MeOH}\right.$ 9.5:0.5) podría sugerirse una actividad sinérgica entre ellas. Los análisis estadísticos realizados mostraron los siguientes resultados: $\mathrm{F}=30.672, \mathrm{GL}=9$, $p<0.05, \mathrm{~N}=60$ y K-W=46.715, GL=9, $p<0.05, \mathrm{~N}=60$.

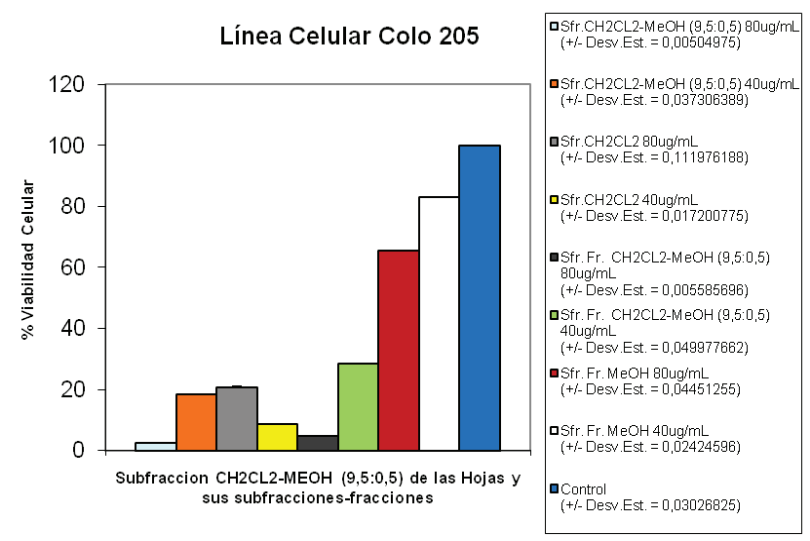

Figura 7. Efecto citotóxico de la subfracción en diclorometano:metanol 9,5:0,5 de las hojas y sus subfracciones probadas a 80 y $40 \mu \mathrm{g} / \mathrm{mL}$ frente a la línea celular Colo 205 .

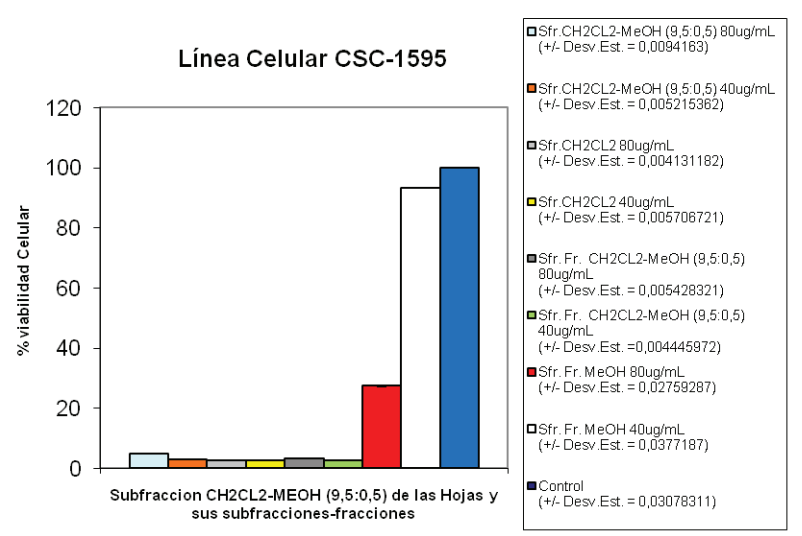

Figura 8. Efecto citotóxico de la subfracción en diclorometanometanol 9,5:0,5 y sus subfracciones a 80 y $40 \mu \mathrm{g} / \mathrm{mL}$ frente a la línea celular CSC-1595.
En la línea CSC-1595, la subfracción diclorometano presentó porcentajes de viabilidad de $2.85 \%$ a una concentración de $80 \mu \mathrm{g} / \mathrm{mL}$ y de $2.68 \%$ a $40 \mu \mathrm{g} /$ $\mathrm{mL}$. La subfracción en diclorometano-metanol (9.5:0.5) presentó porcentajes de viabilidad de $3.31 \%$ a $80 \mu \mathrm{g} / \mathrm{mL}$ y de $2.79 \%$ a $40 \mu \mathrm{g} / \mathrm{mL}$, esta dos fracciones presentaron un perfil citotóxico similar o mayor al de la fracción original.

Las pruebas químicas cualitativas de la subfracción activa mostraron ser positivas para las pruebas de Baljet y Liebermann Burchard lo que permite sugerir que la subfracción contiene en su composición compuestos terpénicos alguno de ellos probablemente con función lactona. Las pruebas estadísticas realizadas en todos los ensayos de citotoxicidad, mostraron que no hay normalidad ni homogeneidad de varianzas y que existen diferencias significativas entre los distintos tratamientos.

\section{AGRADECIMIENTOS}

Los autores agradecen a La Pontificia Universidad Javeriana por la financiación del proyecto "Estudio fitoquimico de las partes aéreas de Bursera tomentosa (Jacq.) Triana et Planck y determinación de la actividad citotóxica frente a líneas celulares tumorales", además, por el apoyo físico en la realización de esta investigación.

\section{REFERENCIAS}

Claeson P, Radstrom P 1992. Bactericidal effect of the sesquiterpene T-cadinol on Staphylococcus aureus. Phytother Res 2: 94-98.

Desta B 1993. Ethiopian traditional herbal drugs: Part II Antimicrobial activity of 63 medicinal plants. $J$ Ethnopharmacol 39: 129-139.

Duwieuja M, Zeitlin Y 1993. Anti-inflammatory activity of resins from some species of the plant family Burseraceae. Plant Med 9: 12-16.

Gray AI, Mitchell AM, Rodriguez-Jujuborre N, De Corredor B, Robles JE, Torrenegra RD, Cole M, Cifuentes C 1997. Ups and downs of natural products. In: Phytochemical Diversity: A Source of New Industrial Products. Special Publication No. 200, Royal Society Chemistry, Cambridge, p. 74-83.

Hostettmann K, Hamburguer M 1991. Bioactivity in plants: the link between phytochemistry and medicine. Phytochemistry 30: 3864-3874.

Jolad SD, Wiedhopf RM, Cole JR 1977. Citotoxic agents from Burseramorelensis (Burseraceae): deoxypodophyllotoxin and a new lignan 5'-desmethoxydeoxypodophyllotoxin. J Pharm Sci 66: 892-893.

Jutiviboonsuk A, Zhang H, Teng Tan G, Ma C, Van Hung N, Cuong NM, Bunyapraphatsara N, Soejarto DD, Fong $\mathrm{H}$ 2005. Bioactive constituents from roots of Bursera tokinensis. Phytochemistry 66: 2745-2751.

Lima E, Gompertz A 1992. In vitro antifungal activity of essential oils against clinical isolates of dermatophytes. 
Rev Microbiol 23: 235-238.

Martínez M 1998. Estudio Preliminar de la Familia Burseraceae en Colombia con Énfasis en la Etnobotánica de la Región Amazónica (San Martín Amacayauco). Santa fe de Bogotá, 84p. Trabajo de Grado, Facultad de Ciencias, Departamento de Biología, Universidad Nacional de Colombia.

Murillo-Alvarez JI, Encarnación DR, Franzblau SG 2001. Antimicrobial and cytotoxic activity of some medicinal plants from Baja California Sur (México). Pharm Biol 39: 445-449.

Poehland B, Carte B 1987. In vitro antiviral activity of dammar resin triterpenoids. J Nat Prod 50: 706-713.

Rahalison L, Hamburger M 1993. Screening for antifungal activity of Panamanian plants. Int J Pharmacogn 31: 6876.

Robles JE, Torrenegra RD, Gray AI, Piñeros C, Ortiz L, Sierra M 2005. Triterpenos aislados de corteza de Bursera graveolens (Burseraceae) y su actividad biológica. Rev Bras Farmacogn 15: 283-286.

Sharma R, Trivedi P 1991. Nematicidal properties of some laef extracts against Meloidogyne incógnita. J Phytol Res 4: 131-137.

Studzinski GP 1999. Cell growth, differentiation and senescente. In: The practical approach series. Series editor: BD. Hames. p. 46-48.

Téllez AN, De Castro C, Riveros T, Torrenegra RD 2006. Efectos citotóxicos in vitro de extractos y fracciones de Espeletia killipii Cuatr. frente a líneas celulares tumorales humanos. Rev Bras Farmacogn 16: 12-16. 